\title{
Chitosan-Carrageenan Polyelectrolyte Complex for the Delivery of Protein Drugs
}

\author{
Cunben Li, ${ }^{1,2}$ San Hein, ${ }^{1}$ and Kean Wang ${ }^{1,3}$ \\ ${ }^{1}$ School of Chemical and Biomedical Engineering, Nanyang Technological University, Singapore 637459 \\ ${ }^{2}$ School of Life Sciences \& Chemical Technology, Ngee Ann Polytechnic, Singapore 599489 \\ ${ }^{3}$ Department of Chemical Engineering, The Petroleum Institute, P. O. Box 2533, Abu Dhabi, UAE
}

Correspondence should be addressed to Kean Wang; kwang@pi.ac.ae

Received 22 July 2012; Accepted 12 August 2012

Academic Editors: S. Lamponi and M. Rouabhia

Copyright (C) 2013 Cunben Li et al. This is an open access article distributed under the Creative Commons Attribution License, which permits unrestricted use, distribution, and reproduction in any medium, provided the original work is properly cited.

\begin{abstract}
A chitosan-carrageenan polyelectrolyte complex (PEC) was prepared by salt induced impeding of polyplex formation method and was encapsulated with bovine serum albumin (BSA) to study the potential to be tailored to the $\mathrm{pH}$ responsive oral delivery of protein drugs. The FTIR spectra showed the successful formation of the PEC under the experimental condition. The release kinetics of BSA from the PEC was studied in the simulated gastrointestinal fluids with and without digestive enzymes. The prepared PEC showed the nature of $\mathrm{pH}$-sensitivity. A typical controlled release of BSA from the PEC (180 $\mathrm{g}$ of BSA from $3 \mathrm{mg}$ of PEC) was obtained in the simulated intestinal fluid (SIF, pH 7.5), which was due to the significant swelling and disintegration of PEC, but little amount of BSA was released (11 $\mathrm{g}$ of BSA from $3 \mathrm{mg}$ of PEC) in the simulated gastric fluid (SGF, pH 1.2), confirming acidic stability of the prepared PEC. The presence of digestive enzymes was found not to affect the response of PEC to ambient $\mathrm{pH}$ value, but to speed up the release of BSA from carriers.
\end{abstract}

\section{Introduction}

With the rapid development in biotechnology and recombinant technology, more and more therapeutic peptides and proteins have been produced as drugs at commercial scale. Among various routes for administrating the drugs, oral route is preferred due to its high levels of patient acceptance and long term compliance [1]. Moreover, the dosage forms can be formulated with relative ease and are manufactured without sterile conditions [2]. However, this delivery route faces ineffectiveness for the peptide and protein drugs because the drugs can be easily hydrolyzed by the extreme acidity in the stomach and proteolytic enzymes in the gastrointestinal (GI) tract. The penetration barrier also prevents them from crossing the intestinal and then basal membranes for entry into the blood [3]. To improve the oral bioavailability from less than $1 \%$ to at least $30-50 \%$ for a polypeptide drug delivery through the GI tract has attracted intensive research [4].
Polyelectrolyte complexes (PEC) are formed by the ionic interactions as ionically cross-linked networks when two oppositely charged polyelectrolytes bind each other in an aqueous solution [5]. The net charge fixed on the complex, which is an important factor determining the swelling and the induced volume change of the PEC, is affected by $\mathrm{pH}$ value of ambient solution due to the variation in the degree of ionization of functional groups [6]. Thus, the nature of highly $\mathrm{pH}$-sensitive swelling brings PEC to the application of oral drug delivery $[7,8]$ because the $\mathrm{pH}$ varies at each organs or the diseased part of human body. Due to the consideration of biocompatible and nontoxic substance as the components of polyelectrolyte complexes in such applications, several chitosan-based PEC have been studied for controlled release formulations in combination with either synthetic or natural polyanions, such as alginate [9], polyacrylic acid [10], carboxymethyl-cellulose [11], dextran sulfate [12], xanthan [13], and collagen [14]. One of the natural polyanions under investigation is $\mathcal{\kappa}$-carrageeenan, an acidic polysaccharide 
with sulfate groups [15]. In an acidic solution, the negatively charged sulfate groups of $\kappa$-carrageenan bind to the positively charged amino groups of chitosan and form an acid-base type PEC. Upon increasing $\mathrm{pH}$, the amino groups are deionized and the binding affinity between two polyelectrolyte molecules becomes weaker, which would lead to the swelling and disintegration of the PEC and finally the release of loaded drug $[16,17]$. By adjusting factors that cause the swelling properties of PEC, it is possible for us to precisely modulate the drug release to the target site. Because of mucoadhesive properties of chitosan [18], chitosan-based PEC might give added advantage to enhance the intestinal absorption of drugs, to prevent the presystemic metabolism of peptides and to increase the residence time of the delivery system. Consequently, it will result in the increased oral bioavailability of peptide and protein drugs [19].

It is known in the prior art that $\mathrm{pH}$-sensitive chitosancarrageenan PEC and encapsulation of drug can be prepared by simple mixing of two aqueous solutions of polyelectrolytes together with drug solutions under optimal conditions. However, limited success has been reported on the stability of chitosan-carrageenan PEC in acidic gastric $\mathrm{pH}[9,20]$. It has been found that the solution properties of carrageenan differ upon degree of sulfation, the presence of salts, and its concentration [21]. Moreover, being a polyelectrolyte, rheology of chitosan solutions are affected by the presence of salt [22]. In this study, the chitosan-carrageenan PEC was prepared by mixing aqueous solutions of chitosan and $\kappa$-carrageenan in the presence of $\mathrm{NaCl}$. It is expected that, due to the presence of electrolyte counterions, the interaction between two polyelectrolytes will be delayed and the characteristic of PEC formed will have different properties. This process is named as the "salt induced impeding of polyplex formation" method. Bovine serum albumin (BSA) was used as a model protein drug to investigate the release kinetic in simulated gastrointestinal tract environments.

\section{Experiments}

2.1. Materials. Chitosan powder with $90 \%$ deacetylation degree (MW 180,000) was obtained from Bio-line Co., Ltd., Thailand. $\kappa$-carrageenan, bovine serum albumin, pepsin, pancreatin, and Bradford reagent were purchased from Sigma-Aldrich. Other materials were of analytical grade from Merck. Simulated gastric fluid (SGF pH 1.2), which contains $7 \mathrm{~mL}$ of hydrochloric acid (37.4\%), $2 \mathrm{~g}$ of sodium chloride in $1 \mathrm{~L}$ of deionized water, was prepared with and without $3.2 \mathrm{~g}$ of pepsin. Similarly, simulated intestinal fluid (SIF pH 7.5), which contains $6.8 \mathrm{~g}$ of potassium dihydrogen phosphate and $190 \mathrm{~mL}$ of $0.2 \mathrm{M}$ sodium hydroxide in $1 \mathrm{~L}$ of deionized water, was prepared with and without $10 \mathrm{~g}$ of pancreatin [23].

\subsection{Methods}

2.2.1. Preparation of BSA Loaded Chitosan-Carrageenan Polyelectrolyte Complex. BSA was loaded into the chitosancarrageenan polyelectrolyte complex matrix using incorporation method. $500 \mathrm{~mL}$ of $0.3 \%(\mathrm{w} / \mathrm{v})$ chitosan solution was prepared by dissolving $1.5 \mathrm{~g}$ of chitosan powder in $1 \%$ acetic acid. $400 \mathrm{~mL}$ of $\kappa$-carrageenan solution was prepared by dissolving $1.5 \mathrm{~g}$ of $\kappa$-carrageenan in deionized water with $25 \mathrm{~g}$ of sodium chloride at $90^{\circ} \mathrm{C}$ and cooled to room temperature. $100 \mathrm{~mL}$ of BSA solution was prepared by dissolving $0.5 \mathrm{~g}$ of BSA in deionized water. The $\kappa$-carrageenan solution and BSA solution were mixed gently to obtain $0.3 \%(\mathrm{w} / \mathrm{v}) \kappa$ carrageenan solution with BSA of $1000 \mu \mathrm{g} / \mathrm{mL}$. Subsequently, chitosan solution was added dropwise to the $\kappa$-carrageenan solution at the rate of $3 \mathrm{~mL} / \mathrm{min}$ under stirring. When the resultant particles settled, the supernatant was decanted and $0.01 \%$ acetic acid solution was added to the particles to wash away the unreacted free polymer and sodium chloride in the suspension. This step was repeated everyday for a week. After that, the suspension was freeze-dried to obtain the agglomerates. The freeze-dried PEC agglomerates were ground into particles, which were then subjected to the structural characterization and the release of BSA.

2.2.2. Characterization. The PEC particles were coated with platinum under vacuum and their scanning electron micrographs were obtained using a JEOL (JSM 5600) scanning electron microscope (SEM).

FTIR spectra were recorded using $\mathrm{KBr}$ pellet in a Perkin Elmer Spectrum One FTIR with ATR spectrophotometer. Chitosan, $\kappa$-carrageenan, and chitosan-carrageenan PEC were finely ground together with $\mathrm{KBr}$, respectively. FTIR spectra were recorded in the range of $4000-500 \mathrm{~cm}^{-1}$. The number of scans was set at 16 and the spectral resolution was $4 \mathrm{~cm}^{-1}$.

2.2.3. Protein Release in SGF and SIF. Firstly, the release profiles of BSA from the encapsulated PEC particles in SGF and SIF were investigated, respectively. Each sample containing $3 \mathrm{mg}$ of BSA encapsulated particles and $1 \mathrm{~mL}$ of simulated fluids was incubated in an orbital shaker incubator (TU-900) at $37^{\circ} \mathrm{C}$ with a stirring rate of $200 \mathrm{rpm}$. After the predetermined time intervals, the fluids was filtered with $0.45 \mu \mathrm{m}$ membrane and the BSA concentration in the filtrate was determined with Bradford reagent using a Nicolet Evolution 500 UV spectrophotometer.

Next, the release profiles of BSA from the encapsulated PEC particles were investigated under the mimic physiological gastrointestinal conditions (in SGF followed by in SIF). After the encapsulated particles were incubated in SGF at $37^{\circ} \mathrm{C}$ with a stirring rate of $200 \mathrm{rpm}$ for 4 hours, the particles were centrifuged at 20,000 g for $10 \mathrm{~min}$ before transferred to SIF and incubated at the same conditions. The release medium in SIF was taken out for the analysis using the method described above.

Finally, the release profiles of BSA encapsulated particles in simulated GI tract with digestive enzymes were investigated. All the experiments were conducted in triplicates.

\section{Results and Discussions}

3.1. BSA Loaded PEC Particles. The presence of electrolyte counterions from $\mathrm{NaCl}\left(\mathrm{Na}^{+}\right.$and $\left.\mathrm{Cl}^{-}\right)$can effectively prevent 


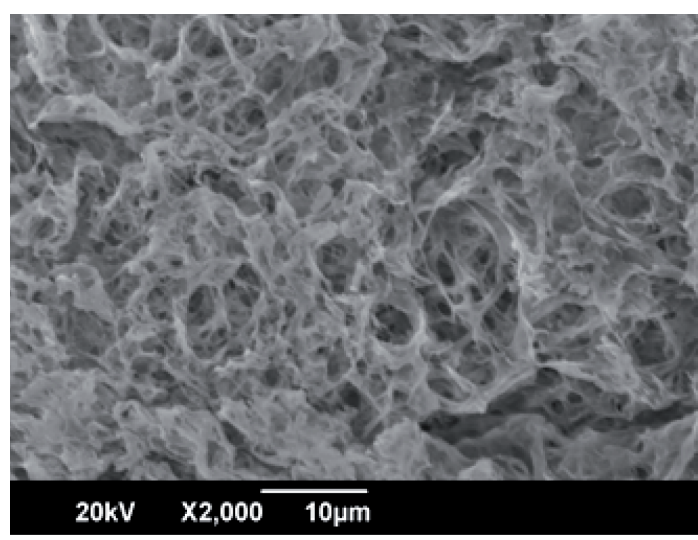

FIGURE 1: SEM image of the BSA loaded chitosan- $\mathcal{\kappa}$-carrageenan agglomerate.

the immediate interaction of the oppositely charged chitosan and $\kappa$-carrageenan due to the weaker ionic attraction induced by the counterion atmosphere around the polyelectrolytes. With this principle, a homogeneous chitosan-carrageenan PEC hydrogel was prepared and found to be stable in acidic $\mathrm{pH}$ with substantial swelling [15]. In this study, the BSA loaded chitosan-carrageenan particles were formed in suspension in the presence of $\mathrm{NaCl}$. The concentrations of chitosan, $\kappa$-carrageenan, the ratio between the two solutions, and the flow rate of chitosan solution were optimized (with a number of trials) to get homogeneous particle suspension under visual judgment. After washing away the unreacted components and freeze-drying concentrated particle suspension, dried particle agglomerates were obtained.

3.2. Characteristics of the PEC. The SEM image of the BSA loaded chitosan-carrageenan PEC particles was shown in Figure 1. It is seen that the particles presented interconnected pores of micrometer scale with some lumpy areas. The FTIR results indicated the successful formation of chitosancarrageenan polyelectrolyte complex.

FTIR spectra of $\kappa$-carrageenan (a), chitosan (b), and polyelectrolyte complex of chitosan and $\kappa$-carrageenan (c) were shown in Figure 2 (wavelength $1800-600 \mathrm{~cm}^{-1}$ ). The sulfate groups of $\kappa$-carrageenan attributed to the peaks at 1261, 924, and $851 \mathrm{~cm}^{-1}$. The amide I peak of chitosan appeared at $1655 \mathrm{~cm}^{-1}$. The broad bands around $1200-1000 \mathrm{~cm}^{-1}$ in both chitosan and carrageenan are from stretching of C-O-C. After the formation of chitosan-carrageenan polyelectrolyte complex, a new absorption band at $1525 \mathrm{~cm}^{-1}$ due to $-\mathrm{NH}_{3}{ }^{+}$ groups appeared. Moreover, the amide I peak from chitosan at $1655 \mathrm{~cm}^{-1}$ was shifted to $1641 \mathrm{~cm}^{-1}$ and the reduction of sulfate peak intensity at $1267 \mathrm{~cm}^{-1}$ was observed. It indicates the interaction between protonated amine groups of chitosan and sulfates groups of $\kappa$-carrageenan in the successful formation of chitosan-carrageenan polyelectrolyte complex.

3.3. Release of BSA in SGF and SIF as the Separated Medium. The release behaviors of BSA from the PEC particles in SGF

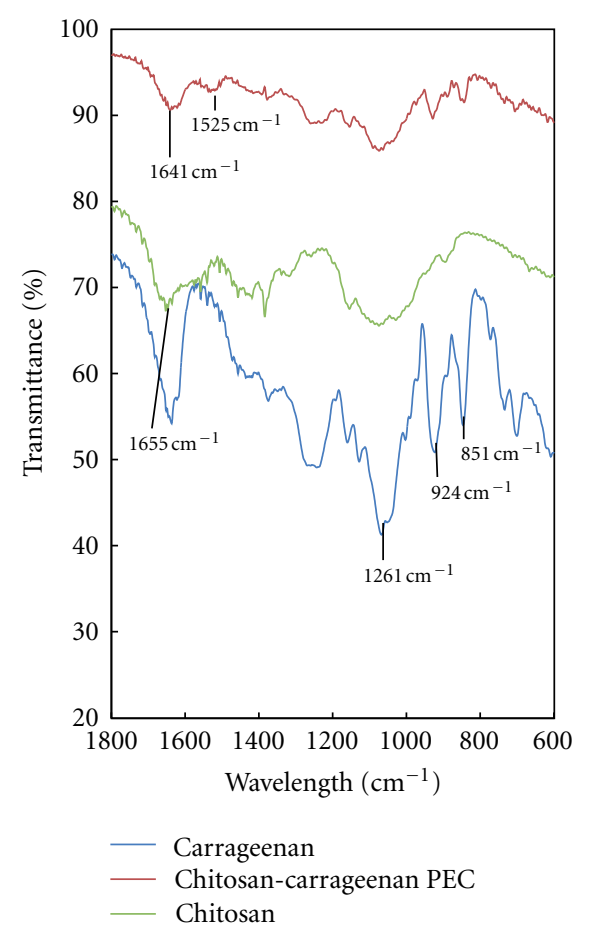

FIGURE 2: FTIR spectra of (a) $\kappa$-carrageenan, (b) chitosan, and (c) polyelectrolyte complex of chitosan and $\kappa$-carrageenan from 1800 to $600 \mathrm{~cm}^{-1}$.

and SIF without digestive enzymes were measured and shown in Figure 3. The typical fast first-order followed by zero-order release kinetics was observed in both SGF and SIF media. However, the initial burst release observed in SIF was much faster than that in SGF. Within first $5 \mathrm{~min}$, the release rate in SIF was 14 times faster than that in acidic SGF. Although no dramatic increase in BSA release was found in SGF after 5 min, BSA was further released in SIF for another one hour. Only $11 \mu \mathrm{g}$ of BSA was released in SGF, while $180 \mu \mathrm{g}$ of BSA was released in SIF.

Gan and Wang [24] had proposed the following protein release mechanisms: (a) desorption of protein molecules from the surface of particles, (b) diffusion through the swollen PEC, and (c) disintegration of the PEC. In acidic SGF medium ( $\mathrm{pH} 1.2$ ), chitosan and $\kappa$-carrageenan were oppositely charged and bound tightly. Therefore, further release was limited because of the absence of swelling or disintegration of PEC. The little amount of BSA released in SGF might be due to desorption of loosely bound BSA from the surface of particle. In SIF ( $\mathrm{pH}$ 7.5), the ionic attraction between chitosan and $\kappa$-carrageenan became weaker because the pKa of chitosan is around 6.3 and little amino groups of chitosan got protonated. This will lead to significant swelling and disintegration of PEC, which allows large amount of encapsulated BSA to be released. As a result, the amount of BSA released in SIF was much higher than that in SGF. Those experimental results demonstrated that the chitosancarrageenan polyelectrolyte complex can protect the loaded protein drug in acidic gastric condition and release it in higher $\mathrm{pH}$ of intestinal environment. 


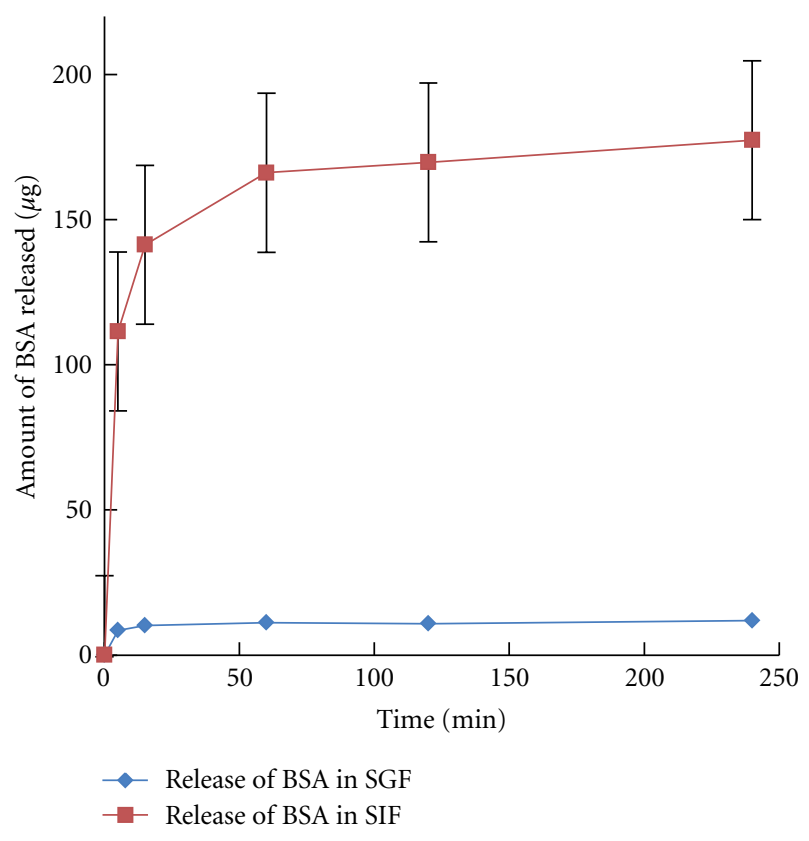

FIGURE 3: The release profile of BSA in SGF and SIF.

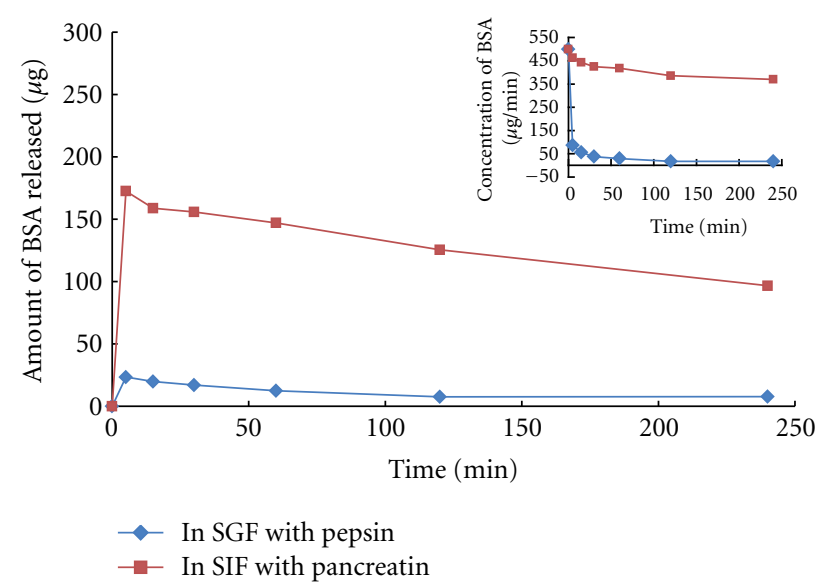

FIGURE 4: The release profile of BSA in SGF and SIF with digestive enzymes.

The release kinetics of BSA loaded PEC particles were also investigated in SGF and SIF in the presence of digestive enzymes. SGF was supplemented with pepsin and SIF with pancreatin. The results were shown in Figure 4. The trends of release kinetics were similar to those observed as in SGF and SIF without enzymes. In SGF with pepsin, maximum amount $(23 \mu \mathrm{g})$ of BSA released was detected at 5 minutes, and then it decreased gradually to $8 \mu \mathrm{g}$ at the end of 4 hours. In SIF with pancreatin, the maximum BSA release $(170 \mu \mathrm{g})$ occurred at 5 minutes, and then it decreased to $95 \mu \mathrm{g}$ after 4 hours. The release of BSA in SIF was again significantly higher than in SGF.

Compared with the BSA release profiles in SGF and SIF without digestive enzymes, more BSA was released in both SGF and SIF with enzymes in initial release period. It

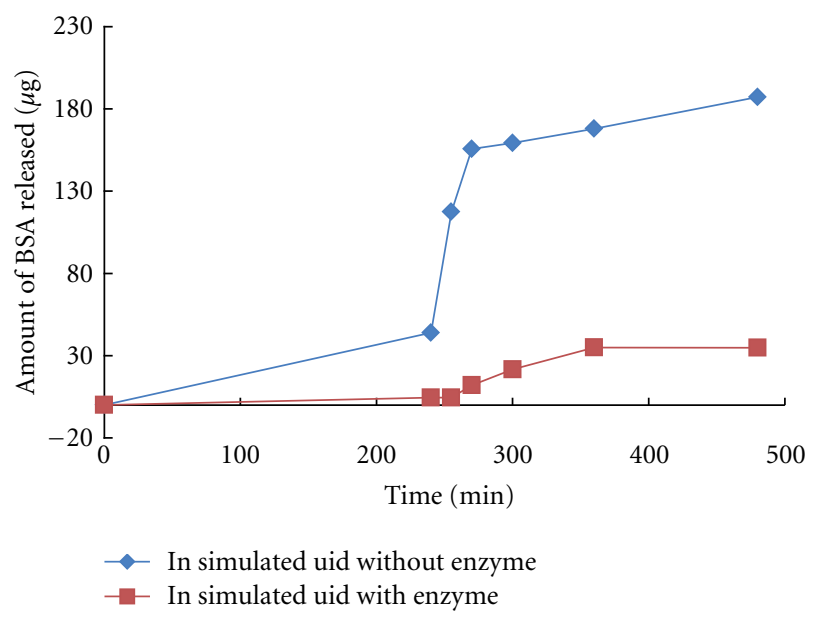

FIGURE 5: The cumulative release profile of BSA in SGF ( $4 \mathrm{hrs}$ ) and followed in SIF.

indicates that the digestive enzymes help to disintegrate the chitosan-carrageenan PEC and speed up the release from the carriers. The decreasing trends of protein concentration after the maximum release were attributed to the degradation of BSA by the digestive enzymes in the release media. Although no significant protein degradation was observed in plain SGF and SIF media, most of BSA was degraded in SGF with pepsin and up to $20 \%$ degradation of BSA was observed in SIF with pancreatin after $1 \mathrm{~h}$ (shown in Figure 4).

3.4. Release of BSA in SGF and Followed by in SIF as a Consecutive Release Medium. In order to mimic the physiological gastrointestinal conditions, the release study of the BSA loaded PEC was conducted in SGF for the first 4 hours and then the particles were transferred to SIF for another 4 hours. Similarly, the release was conducted in the media with and without digestive enzymes for comparison. The results were shown in Figure 5.

In the absence of enzymes, around $40 \mu \mathrm{g}$ of BSA was released after $4 \mathrm{~h}$ of incubation in SGF. After transferring to SIF, about $65 \mu \mathrm{g}$ of BSA was abruptly released in 5 minutes. It continued to increase with incubation time and reached $185 \mu \mathrm{g}$ of cumulative release in a total of 8 hours incubation time. This amount was similar to the one released in 4 hours in SIF without pancreatin.

In the presence of digestive enzymes, only $5 \mu \mathrm{g}$ of BSA was released after 4 hours of incubation in SGF with pepsin. After transferring to SIF with pancreatin, no increase of BSA concentration was detected for the next 15 minutes. Then, the amount of BSA released slowly increased to the maximum of about $35 \mu \mathrm{g}$ in 2 hours and remained the same for the next 4 hours of incubation. It was believed that much more BSA was actually released in both SGF and SIF, but was digested by enzymes. When the particles were first incubated in SGF with pepsin, the enzymes could immobilize on the surface of the particles through electrostatic interaction. When the PEC was put in SIF with pancreatin, not only the loaded BSA protein but also the pepsin immobilized on the surface 
of the PEC would release into the release medium of SIF. Apparently, the combined action of pepsin and pancreatin has synergistically degraded the released BSA protein. This would lead to the low amount of BSA detected in SIF although no significant amount of BSA was released in SGF in the presence of digestive enzymes.

Overall, only little amount of BSA was released from chitosan-carrageenan PEC in acidic SGF (with and without pepsin), but significant amount of BSA was released after the release medium was switched to SIF (with or without pancreatin). To our knowledge, this study is the first time to show that the chitosan-carrageenan PEC particles prepared in the presence of $\mathrm{NaCl}$ can be tailored to the $\mathrm{pH}$ responsive oral delivery of protein drugs.

The trends of the results are encouraging in response to $\mathrm{pH}$ value. However, the presence of digestive enzymes in the gastrointestinal tract is still detrimental to the activity of protein drugs because the released protein or peptide could be digested by the enzymes. The longer the residence time of drugs in the gastrointestinal tract, the higher the degree of the in situ degradation. Therefore, the released protein drug from the PEC should pass gastrointestinal mucosa as quickly as possible to reach the blood circulation to get the desired bioactivity. In the real life scenario, the presence of chitosan could potentially help the faster passage of the protein drug from the intestinal mucosa to the blood circulation because of the mucoadhesive properties of chitosan. Chitosan is known to interact with cystein-rich mucus to delay the mucus turnover rate and transiently open the tight junction of the intestinal wall. This process would help the released protein drug to transport across the intestinal barrier to reach higher bioavailability. In vivo studies are needed in the future to prove this speculation.

\section{Conclusions}

The $\mathrm{pH}$ responsive chitosan-carrageenan polyelectrolyte complex was successfully prepared by salt induced impeding of polyplex formation method. In the simulated gastric fluid ( $\mathrm{pH} 1.2$ ), only $11 \mu \mathrm{g}$ of BSA was released from $3 \mathrm{mg}$ of PEC, while in the simulated intestinal fluid (pH 7.5), $180 \mu \mathrm{g}$ of BSA was released from $3 \mathrm{mg}$ of PEC in four hours. In simulated gastrointestinal media (SGF followed by SIF), $185 \mu \mathrm{g}$ of BSA was released from $3 \mathrm{mg}$ of PEC, which is similar to the one released in SIF. However, in the presence of digestive enzyme the amount of released BSA increased in the first period and significantly decreased with the time going on. These results showed that the PEC matrix is suitable for oral delivery of protein and peptide drugs.

\section{References}

[1] M. Morishita and N. A. Peppas, "Is the oral route possible for peptide and protein drug delivery?" Drug Discovery Today, vol. 11, no. 19-20, pp. 905-910, 2006.

[2] N. N. Salama, N. D. Eddington, and A. Fasano, “Tight junction modulation and its relationship to drug delivery," Advanced Drug Delivery Reviews, vol. 58, no. 1, pp. 15-28, 2006.
[3] V. H. L. Lee and A. Yamamoto, "Penetration and enzymatic barriers to peptide and protein absorption," Advanced Drug Delivery Reviews, vol. 4, no. 2, pp. 171-207, 1989.

[4] V. H. L. Lee, D. Satish, M. George, and R. Werner, Oral Route of Protein and Peptide Drug Delivery, Marcel Dekker, New York, NY, USA, 1991.

[5] A. S. Michaels and R. G. Miekka, "Polycation-polyanion complexes: preparation and properties of poly-(vinylbenzyltrimethylammonium) poly-(styrenesulfonate)," Journal of Physical Chemistry, vol. 65, no. 10, pp. 1765-1773, 1961.

[6] E. Vasheghani-Farahani, J. H. Vera, D. G. Cooper, and M. E. Weber, "Swelling of ionic gels in electrolyte solutions," Industrial and Engineering Chemistry Research, vol. 29, no. 4, pp. 554-560, 1990.

[7] H. Brondsted and J. Kopecek, "Hydrogels for site-specific drug delivery to the colon: in vitro and in vivo degradation," Pharmaceutical Research, vol. 9, no. 12, pp. 1540-1545, 1992.

[8] H. Brondsted and J. Kopecek, "pH-Sensitive hydrogelscharateristics and potential in drug delivery," ACS Symposium Series, vol. 480, pp. 285-304, 1992.

[9] C. Tapia, Z. Escobar, E. Costa et al., "Comparative studies on polyelectrolyte complexes and mixtures of chitosan-alginate and chitosan-carrageenan as prolonged diltiazem clorhydrate release systems," European Journal of Pharmaceutics and Biopharmaceutics, vol. 57, no. 1, pp. 65-75, 2004.

[10] S. Torrado, P. Prada, P. M. De La Torre, and S. Torrado, "Chitosan-poly(acrylic) acid polyionic complex: in vivo study to demonstrate prolonged gastric retention," Biomaterials, vol. 25, no. 5, pp. 917-923, 2004.

[11] V. Crescenzi, G. Paradossi, P. Desideri et al., "New hydrogels based on carbohydrate and on carbohydrate-synthetic polymer networks," Polymer Gels and Networks, vol. 5, no. 3, pp. 225-239, 1997.

[12] T. Sakiyama, H. Takata, T. Toga, and K. Nakanishi, "pHsensitive shrinking of a dextran sulfate/chitosan complex gel and its promotion effect on the release of polymeric substances," Journal of Applied Polymer Science, vol. 81, no. 3, pp. 667-674, 2001.

[13] F. Chellat, M. Tabrizian, S. Dumitriu et al., "In vitro and in vivo biocompatibility of chitosan-xanthan polyionic complex," Journal of Biomedical Materials Research, vol. 51, no. 1, pp. 107-116, 2000.

[14] Q. Zhang, L. Liu, L. Ren, and F. Wang, "Preparation and characterization of collagen-chitosan composites," Journal of Applied Polymer Science, vol. 64, no. 11, pp. 2127-2130, 1997.

[15] T. Sakiyama, C. H. Chu, T. Fujii, and T. Yano, "Preparation of a polyelectrolyte complex gel from chitosan and K-carrageenan and its pH-sensitive swelling," Journal of Applied Polymer Science, vol. 50, no. 11, pp. 2021-2025, 1993.

[16] J. Berger, M. Reist, J. M. Mayer, O. Felt, and R. Gurny, “Structure and interactions in chitosan hydrogels formed by complexation or aggregation for biomedical applications," European Journal of Pharmaceutics and Biopharmaceutics, vol. 57, no. 1, pp. 35-52, 2004.

[17] C. H. Chu, T. Sakiyama, and T. Yano, "pH-Sensitive swelling of a polyelectrolyte complex gel prepared from xanthan and chitosan," Bioscience, Biotechnology, and Biochemistry, vol. 59, no. 4, pp. 717-719, 1995.

[18] P. He, S. S. Davis, and L. Illum, "In vitro evaluation of the mucoadhesive properties of chitosan microspheres," International Journal of Pharmaceutics, vol. 166, no. 1, pp. 75-88, 1998. 
[19] B. J. Aungst, "Intestinal permeation enhancers," Journal of Pharmaceutical Sciences, vol. 89, no. 4, pp. 429-442, 2000.

[20] C. Tapia, V. Corbalán, E. Costa, M. N. Gai, and M. Yazdani-Pedram, "Study of the release mechanism of diltiazem hydrochloride from matrices bases on chitosan-alginate and chitosan-carrageenan mixtures," Biomacromolecules, vol. 6, no. 5, pp. 2389-2395, 2005.

[21] A. Bartkowiak and D. Hunkeler, "Carrageenan-oligochitosan microcapsules: optimization of the formation process," Colloids and Surfaces B, vol. 21, no. 4, pp. 285-298, 2001.

[22] C. A. Kienzle-Sterzer, D. Rodriguez-Sanchez, and C. K. Rha, "Flow behavior of a cationic biopolymer: chitosan," Polymer Bulletin, vol. 13, no. 1, pp. 1-6, 1985.

[23] US Pharmacopoeia, 23rd edition, 1995.

[24] Q. Gan and T. Wang, "Chitosan nanoparticle as protein delivery carrier-systematic examination of fabrication conditions for efficient loading and release," Colloids and Surfaces B, vol. 59, no. 1, pp. 24-34, 2007. 

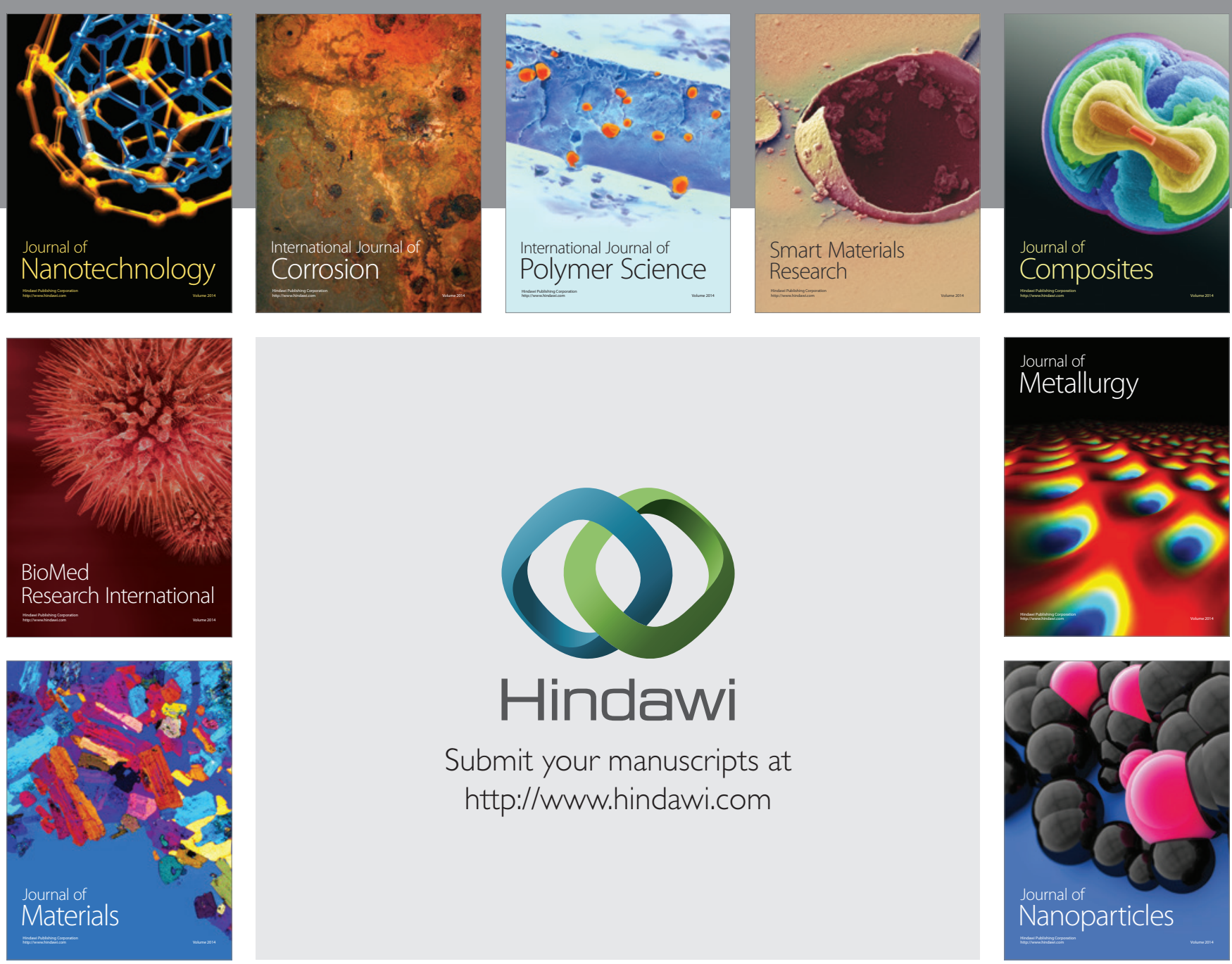

Submit your manuscripts at http://www.hindawi.com
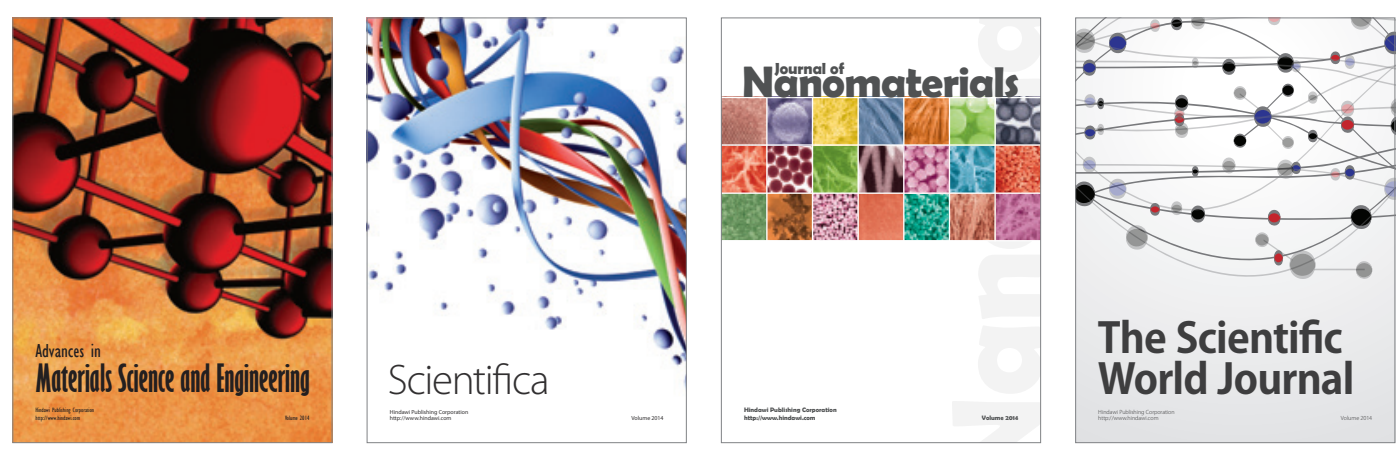

\section{The Scientific World Journal}
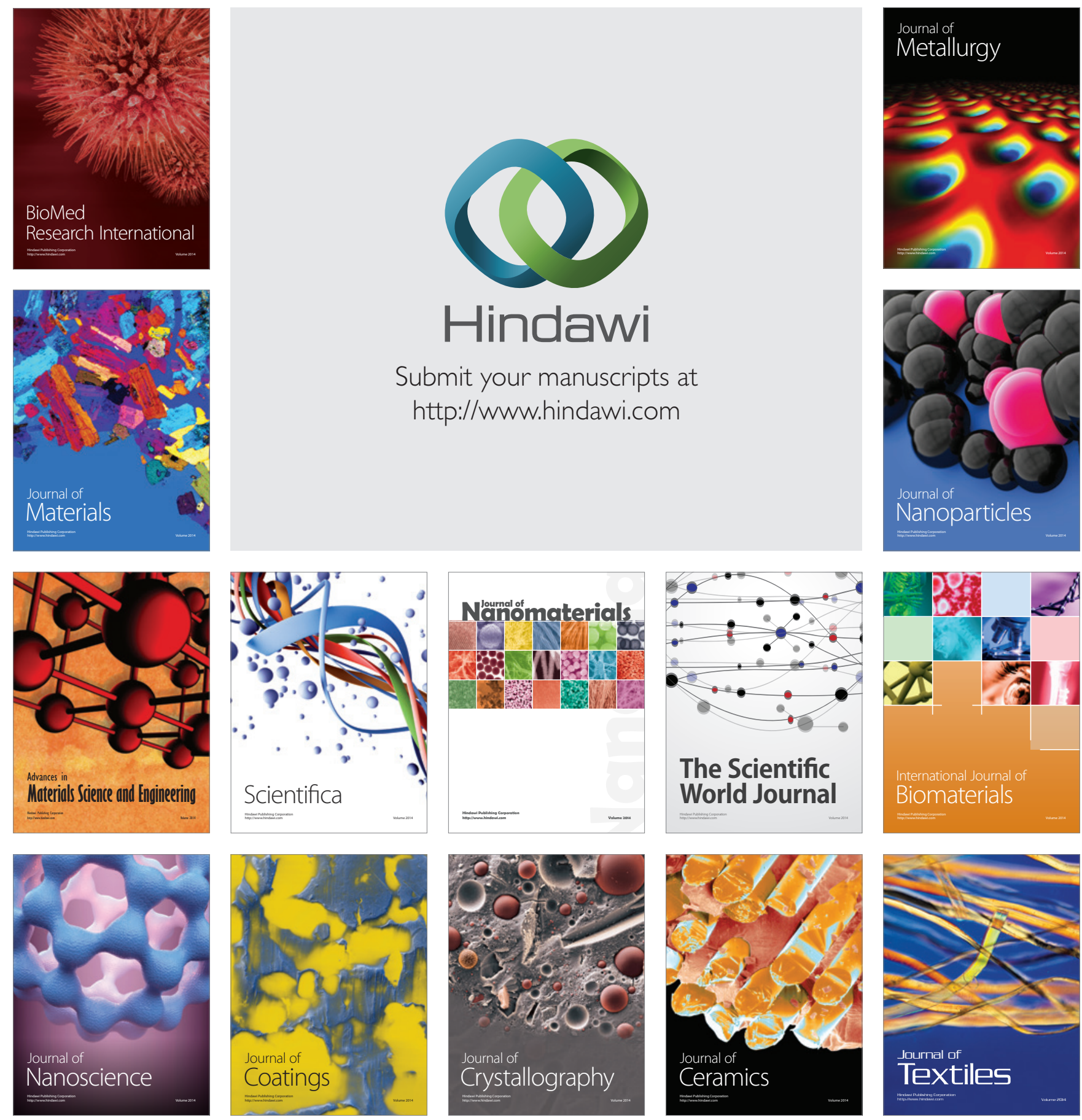